\title{
Juan Caramuel Lobkowitz, Rítmica, Primer Cálamo, tomo II, Secretariado de Publicaciones de la Universidad de Valladolid, 2007.
}

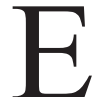

XCELENTE y oportuna la reciente edición de la Rítmica de Juan de Caramuel, al cuidado de Isabel Paraíso, Catedrática de Teoría de la Literatura y Literatura Comparada de la Universidad de Valladolid cuya trayectoria investigadora ha estado dedicada en buena medida al campo de la métrica, al que ha contribuido con obras que constituyen una referencia ineludible, tales como Teoría del ritmo de la prosa (1976), El verso libre hispánico. Orígenes y corrientes (1985), La métrica española en su contexto románico (2000) y, más recientemente y como anejo de esta revista, Reveladoras elecciones. Estudios de métrica y literatura (2007).

La propia editora anunciaba en un número anterior de Rhythmica la publicación de la obra que ahora tenemos a nuestra disposición y justificaba su conveniencia y la necesidad de rescatarla del olvido al que la habían condenado, fundamentalmente, las circunstancias de estar escrita en latín y no haber sido reeditada desde el siglo de su composición, el XVII. El hecho de que ésta sea la primera traducción al español supone, pues, hacer mucho más accesible el texto a los investigadores interesados en la métrica en general y, más concretamente, en la teoría métrica de los Siglos de Oro.

Es indiscutible, en todo caso, la importancia de las ideas métricas de Juan de Caramuel, pese a ese relativo olvido del que han sido objeto por las causas antes apuntadas. La frecuentes alusiones a distintos autores destacados del renacimiento y del barroco demuestran la amplitud de sus lecturas y la medida en que se mantiene atento a las distintas teorías y opiniones relativas a la versificación y a la prosodia, pero, con ser esto un claro indicio del interés que nos reserva la consulta de su Rítmica, lo que más valor otorga a su obra, probablemente, sea la visión crítica con que se enfrenta a las doctrinas ajenas, así como la manera honesta, personal y falta de prejuicios con que somete los hechos que describe a un análisis reflexivo y con frecuencia perspicaz. Sus muchas lecturas no implican una aceptación sin más de las mismas, e incluso las referencias generalmente elogiosas que hace a Díaz Rengifo, de quien acepta bastantes ideas y a quien reconoce cierto magisterio, no impiden que muestre su discrepancia cuando lo considera oportuno, y cabe decir que suele ser con buen tino. Así, por ejemplo, en el primer capítulo del segundo libro, Caramuel cita y examina detenidamente las distintas opiniones sobre la cuestión de si terminaciones del tipo -édia, -ória, -índia, -ácia, etc. serían esdrújulas, como defiende Rengifo; Caramuel, sin embargo, demuestra mediante varios argumentos y comprobaciones que se trata de finales paroxítonos. 
La independencia de su criterio y la originalidad de algunos planteamientos provocan que se aleje un tanto de las doctrinas establecidas, y en ocasiones le conducen hasta conclusiones sorprendentes para la época. Es probable que esa misma originalidad haya contribuido, paradójicamente, a la poca repercusión de su teoría. Hay, entre todas sus ideas, una que destaca por su importancia y su acierto, pero que, formulada tan prematuramente y de manera tan aislada, no ha tenido el menor eco, pese a que algunas de las propuestas métricas más destacables de la actualidad han llegado hasta el mismo punto. Se trata de la afirmación de que "Un gramático y un Rítmico computan de forma diferente las sílabas de los versos. El primero tiene en cuenta el número total de sílabas, mientras que el segundo toma como referencia la sílaba en la que recae el último acento" (pág. 85), y "lo que se añada después de la última sílaba acentuada, sea cual sea su entidad gramatical, es indiferente desde el punto de vista rítmico, al no aumentar el número de sílabas" (pág. 66). En versos equivalentes, la variación de terminaciones agudas, llanas y esdrújulas, añade Caramuel, podrían inducir a confusión, pero"acúdase, pues, a la Rítmica, que prescribe que se cuenten las sílabas hasta el último acento, y entonces se llegará a la conclusión de que todos son iguales" (pág. 85). Esto le lleva a cambiar la nomenclatura tradicional de los versos, llamando, por ejemplo, decasílabo, al que la tradición conoce como endecasílabo italiano.

En cuanto al plan y la estructura de la obra, dado que tanto en la introducción del libro como en el artículo publicado por su editora en el número dos de Rhythmica se ha tratado por extenso, baste recordar aquí que Rítmica es la parte de Primus calamus que se dedica a la versificación silábico-acentual de las lenguas romances, frente a Metamétrica, que se ocupa de la versificación cuantitativa en latín. Ambas iban a completarse con una proyectada Gramática que, sin embargo, no llegó a formar parte del conjunto como publicación independiente. Rítmica, que es el libro que ahora se edita, está constituido por dos series de epístolas que lo abren y lo cierran, y que envuelven tres libros. De ellos, los dos primeros son la parte fundamental y más interesante, al menos en cuanto a la doctrina, puesto que el tercero es, en esencia, un diccionario de rimas que se extiende a lo largo de cien páginas y que está tomado en gran medida de Díaz Rengifo.

Es entre las epístolas y en el primer libro donde hay que buscar las ideas más valiosas. Las epístolas no son un mero añadido, sino una verdadera introducción que establece los principios sobre los que se va a construir la obra, algunos de cuyos hallazgos van anticipando. Entre esos principios está la definición y explicación de la Poética, que se entiende como un saber esencialmente universal, y "un hábito intelectual que dirige al poeta para que elabore buenos poemas sin dificultad" (pág. 21). También se aclara en las epístolas cuál es la diferencia entre dos de sus partes constituyentes, rítmica y métrica, y se define el ritmo. En epístolas sucesivas se discute la calidad o la abundancia de los poetas, así como la importancia de su figura abstracta, se reflexiona sobre el debate tradicional de la imitatio - Caramuel se pronuncia a favor de la imitación de un solo modelo-, y analiza la diferencia entre mentira y ficción. 
El primer libro, titulado "Sobre las letras, las figuras y los tonos", consiste en un profundo análisis que comienza por aclarar las cuestiones básicas, relativas a la representación gráfica, la pronunciación y la sílaba, y que luego se extiende fundamentalmente sobre asuntos tales como los encuentros entre vocales -incluye consideraciones sobre la compensación y la sinafía-, la acentuación y la estilística o la tipología de la rima. Como va a hacer a lo largo de toda la obra, Caramuel se preocupa por comparar lo que sucede y se practica en la versificación española con lo característico de otras lenguas y tradiciones, aplicando en la práctica su consideración inicial del carácter universal de la poética.

El libro segundo se titula "Sobre los versos rítmicos y su variedad infinita", y trata sobre los tipos de verso según su acentuación final y su número de sílabas (hasta el último acento), así como su combinatoria estrófica teniendo en cuenta -una vez más- la rima y el número de versos que integran la estrofa. Este segundo libro decuplica la extensión del primero, debido en gran medida a que incluye una infinidad de poemas de diversos autores que sirven para ejemplificar la doctrina, aunque cabe pensar que en muchos casos son superfluos y que tal profusión de poemas convierte algunas partes del segundo libro en florilegios que no pueden sino distraer al lector que está interesado en las ideas literarias. Sirva como ejemplo el extenso capítulo V, que trata de la canción, y que después de definirla y caracterizarla dedica setenta páginas a explicar sus variantes, que en esencia no consisten sino en que las estancias pueden variar desde los cinco a los veinte versos, lo que para Caramuel justifica la transcripción de casi un centenar de composiciones completas, la mayor parte en español e italiano y alguna en alemán o latín. Más interesante es el capítulo posterior, en el que analiza la diferencia entre canción, madrigal y silva. Luego se ocupa de la lira -sobre todo de la de seis versos- y, por fin, del soneto, siguiendo en buena parte a Rengifo.

El tercer y último libro, como se ha dicho, es una suerte de diccionario de rimas, un inventario de consonantes y asonancias que atienden, en diversos listados, a su condición de agudas, llanas y esdrújulas, o a la categoría gramatical a la que pertenecen -el capítulo V se dedica a los nombres propios-. Hay también tablas de homófonos, y de palabras fénix, que Caramuel llama dissonantes, y que, tal vez porque conducen a la imposibilidad de la estrofa, la sirven para poner punto y final al libro.

Las últimas epístolas, añadidas con posterioridad a la primera edición, acumulan de manera asistemática una serie de análisis y reflexiones de variado interés. Son sobre todo ejercicios de crítica literaria en los que va engarzando ideas relativas a la métrica, añadiendo nuevos ejemplos de versos y estrofas y planteando algunos casos dudosos, como el de lo que sucede cuando un verso termina con dos monosílabos. Vuelve en estas epístolas a incidir en la idea de que el último acento constituye el final del verso y se detiene en algunas rarezas de las que tanto le atraen, como los versos bilingües simultáneos o la recurrencia de los versos, esto es, la posibilidad de construir versos que tengan también sentido cuando se leen desde la última palabra a la primera. 
Si bien es posible encontrar algún que otro error en los escritos de Caramuel -como la confusión del Francisco de la Torre que edita Quevedo con un poeta homónimo anterior-, lo cierto es que la Ritmica es un libro valioso, que aporta una información muy valiosa más allá incluso de las cuestiones métricas, y su lectura detenida es garantía de hallazgo renovado. La curiosidad del autor le lleva a formular continuas preguntas que han sido contestadas de una forma que no le satisface y que lo empujan, mediante el debate, a planteamientos novedosos y con frecuencia acertados. No queda, por lo tanto, sino celebrar el rigor y el cuidado que el que se ha traducido y editado esta edición, imprescindible desde ahora para todo estudioso de la métrica.

JUAN FRAU 